\title{
KK-LC-1 may be an effective prognostic biomarker for gastric cancer
}

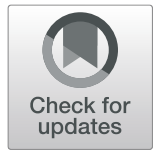

Jun Ji ${ }^{1,2}$, Jiahui Chen ${ }^{3}$, Anqiang Wang ${ }^{3}$, Wei Zhang ${ }^{4}$, Hongge Ju' ${ }^{4}$, Yang Liu ${ }^{4^{*}}$ and Leping $\mathrm{Li}^{1,5^{*}}$ (D)

\begin{abstract}
Background: The objective of the study was to detect the expression of Kita-Kyushu lung cancer antigen-1 (KK-LC1) in gastric cancer (GC) specimens and analyse the associations between KK-LC-1 expression and clinicopathological parameters and clinical prognosis.

Methods: All of the 94 patients in this study were GC patients who underwent surgical resection. KK-LC-1 protein expression in GC tissue was detected by immunohistochemistry. This report applies the histological score (H-score) to evaluate KK-LC-1 expression. To calculate this indicator, the number of positive cells in each section and their staining intensity were converted to corresponding values. The expression of KK-LC-1 in the cytoplasm of cancer and normal tissues was scored to obtain their respective $\mathrm{H}$ values. The chi-square test, Kaplan-Meier method and Cox regression were used to analyse the linear association between KK-LC-1 expression and clinicopathological data and prognosis.

Results: In the cytoplasm, KK-LC-1 expression in tumour tissues was significantly higher than that in normal tissues $(P<0.001)$. Using the median $\mathrm{H}$-score as the cut-off value, we discovered that GC patients with high levels of KK-LC1 expression in the cytoplasm had favourable overall survival (OS) $(P=0.016)$, and this result was statistically significant in the Cox regression analysis. Additionally, a negative correlation was found between KK-LC-1 protein expression and the pathological grade of the tumour $(P=0.036)$, with significantly more KK-LC-1 protein expression observed in the intestinal type of GC than in the diffuse type ( $P=0.008)$.
\end{abstract}

Conclusions: Our research data showed that KK-LC-1 expression was greater in GC tissues than in normal tissues, and higher KK-LC-1 expression was associated with longer OS of GC patients. KK-LC-1 can be used as a biomarker for a good prognosis in GC patients.

Keywords: Gastric cancer, KK-LC-1, Overall survival, Risk score, Biomarker

\section{Background}

Gastric cancer (GC) is the third leading cause of cancerrelated death worldwide. Most patients with gastric cancer are usually not diagnosed until the late stages of the disease, so the prognosis is usually poor. The 5-year

\footnotetext{
*Correspondence: liuyang_bt@163.com; lileping@medmail.com.cn

${ }^{4}$ Baotou Medical College, Inner Mongolia University of Science \& Technology, Baotou 014060, Inner Mongolia, China

'Department of Gastrointestinal Surgery, Shandong Provincial Hospital,

Cheeloo College of Medicine, Shandong University, Jinan 250021, Shandong, China

Full list of author information is available at the end of the article
}

survival rate of all patients, including surgical patients, does not exceed 30\% [1]. It has been suggested that tumour tissue type, TNM stage and patient physical and mental conditions are all important factors affecting the treatment of GC [2]. Metastatic GC has few treatment options, and the treatment goal is palliative rather than therapeutic. Although a number of chemotherapy drugs have been shown to be effective in treating gastric cancer, one fact we cannot ignore is that there are limitations to using targeted therapy for GC, which mainly targets the vascular endothelial growth factor (VEGF) pathway and HER2. Recent research and information

(c) The Author(s). 2021 Open Access This article is licensed under a Creative Commons Attribution 4.0 International License, which permits use, sharing, adaptation, distribution and reproduction in any medium or format, as long as you give appropriate credit to the original author(s) and the source, provide a link to the Creative Commons licence, and indicate if changes were made. The images or other third party material in this article are included in the article's Creative Commons licence, unless indicated otherwise in a credit line to the material. If material is not included in the article's Creative Commons licence and your intended use is not permitted by statutory regulation or exceeds the permitted use, you will need to obtain permission directly from the copyright holder. To view a copy of this licence, visit http://creativecommons.org/licenses/by/4.0/ The Creative Commons Public Domain Dedication waiver (http://creativecommons.org/publicdomain/zero/1.0/) applies to the data made available in this article, unless otherwise stated in a credit line to the data. 
regarding the genetic background of $\mathrm{GC}$ may give us more opportunities for targeted therapy [3].

In addition, various molecular biomarkers are efficient diagnostic and prognostic tools for gastric cancer, but these biomarkers need further validation before they can be used in daily clinical practice. At present, the only biomarkers used for GC are carcinoembryonic antigens CA 19-9, CA-50 [4] and CA-72 [5]. However, these are limited by insufficient sensitivity and specificity to evaluate GC diagnosis and prognosis, and the efficacy of targeting these biomarkers for clinical treatment is doubtful.

There are already some prognostic markers for GC. For example, studies have shown that the Ki-67 index has significance for the prognosis of cancer [6]. Therefore, the high expression of Ki-67 can be used to predict poor prognosis in GC patients. Meta-analysis and systematic reviews of the literature indicate that MSI-H and EBV-positive gastric cancers are usually associated with improved prognosis and prolonged survival [7]. Low expression of $m i R-433$ and high expression of miR214 are independent predictors of poor prognosis [8]. In addition, a large number of studies have shown that $c-M E T$ overexpression is associated with poor survival prognosis [9-11]. However, the number of effective

Table 1 Clinicopathological characteristics of the tissue microarrays

\begin{tabular}{llll}
\hline Characteristic & $\mathbf{n}(\%)$ & Characteristic & $\mathbf{n}(\%)$ \\
\hline Age (yr) & & N2 & $22(23.4)$ \\
$\leq 65$ & $44(46.5)$ & N3a & $29(30.9)$ \\
$>65$ & $50(53.2)$ & N3b & $6(6.4)$ \\
Sex & & Pathological grades & \\
Female & $23(24.5)$ & I & $23(24.5)$ \\
Male & $71(75.5)$ & IIIII & $13(13.8)$ \\
Tumor Size (cm) & & III & $50(53.2)$ \\
$\leq 5$ & $38(40.4)$ & III-IV & $8(8.5)$ \\
$>5$ & $56(59.6)$ & Pathological Stage & \\
T Stage & & IA & $2(2.1)$ \\
T1a & $1(1.1)$ & IB & $4(4.3)$ \\
T1b & $2(2.2)$ & IIA & $13(13.8)$ \\
T2 & $9(9.6)$ & IIB & $15(16.0)$ \\
T3 & $62(66.0)$ & IIIA & $22(23.4)$ \\
T4a & $18(19.1)$ & IIIB & $29(30.9)$ \\
T4b & $2(2.1)$ & IIIC & $5(5.3)$ \\
M Stage & & IV & $4(4.3)$ \\
M0 & $90(95.7)$ & Survival data (year) & \\
M1 & $4(4.3)$ & $\leq 3$ & $58(62 \%)$ \\
N0 & $20(21.3)$ & $>3$ & $36(38 \%)$ \\
N1 & $17(18.1)$ & & \\
\hline
\end{tabular}

prognostic markers for GC is still very small, and there is a need to identify novel and effective biomarkers to determine the prognosis of $\mathrm{GC}$ and to establish new treatment approaches.

Cancer-testis antigens (CTA) are characterized by their spontaneous immunogenicity and unique expression pattern. CTAs are normally expressed only in the germ cells of the normal human testis and placenta, but are also activated in tumour cells $[12,13]$. $T$ cells and anti-CTA protein antibodies can be detected in cancer patients [14-18], suggesting that abnormal expression of CTA can induce tumour tissues to produce an adaptive immune response. Since CTAs are tumour-specific, they are believed to be potential effective targets for new therapeutic strategies, such as immunotherapy $[19,20]$. At the same time, CTA expression in several types of cancer has potential significance for prognosis [21]. Although CTA expression has been studied in many cancers, few studies have focused on gastric cancer [21-23]. Kita-Kyushu lung cancer antigen-1 (KK-LC-1) is also known as CT83. Futawatari $\mathrm{N}$ et al. found that in early stages of GC, high CT83 expression rates can be frequently detected [24].

Previous research by our team has shown that KK-LC$1 \mathrm{mRNA}$ expression is related to the prognosis of gastric cancer [25]. Therefore, we studied KK-LC-1 protein expression in GC specimens and also analysed the relationship between KK-LC-1 protein expression and clinicopathological parameters and prognosis.

\section{Methods \\ Tissue microarrays}

Tissue arrays containing multiple human gastric cancer tissues (HStm-Ade180Sur-17) were obtained from Shanghai Outdo Biotech. The tissue chip samples were all gastric adenocarcinomas. The samples included 94 gastric cancer tissues and 84 adjacent tissues. The operation time was May 2007 to February 2008, and the date of last follow-up was July 2015. The diameter of each sample spot was $1.5 \mathrm{~mm}$, and the thickness of the tissue section was $4 \mu \mathrm{m}$. The EnVision+ detection system (Dako) was used per the manufacturer's instructions. From these tissue arrays, 85 pairs of GC specimens and corresponding adjacent normal tissue specimens were obtained, as well as ten individual cancer tissue specimens. Surgical type was categorized as curative or noncurative resection. Radical resection (R0) refers to the complete removal of the tumour, no residue under the microscope, and complete removal to the naked eye but residual tumour under the microscope (R1) or visible both by the naked eye and pathology (R2), are considered noncurative from the patient's medical record, and the patient was 
Table 2 Kita-Kyushu lung cancer antigen-1 staining results in tumor and normal tissues

\begin{tabular}{lllll}
\hline $\begin{array}{l}\text { Cytoplasmic } \\
\text { staining }\end{array}$ & \multicolumn{2}{l}{$\begin{array}{l}\text { Positive cell rate (\%) } \\
\text { Median (range) }\end{array}$} & Normal tissues & Normal tissues \\
\cline { 2 - 5 } & Tumor tissues & - & Tumor tissues & $8(9.5)$ \\
\hline Negative & - & $90(10-100)$ & $4(4.3)$ & $76(90.5)$ \\
Positive & $100(40-100)$ & $60(10-100)$ & $90(95.7)$ & $36(42.9)$ \\
$<1$ & $90(80-100)$ & $90(20-100)$ & $57(60.7)$ & $40(47.6)$ \\
$1+$ & $100(40-100)$ & - & $14(14.8)$ & $0(0)$
\end{tabular}

Negative $=0$, Positive: $1 \leqq 1+<2,2 \leqq 2+<3$.

followed up with since the surgery date. The GC patients were staged according to the 7 th edition of the American Joint Committee on Cancer staging manual. The end point of follow-up is overall survival (OS), which refers to the interval between the date of surgery and cancer-related death. This study was approved by the Ethics Committee of Shanghai Outdo Biotech Company.

\section{Immunohistochemistry and H-scoring of KK-LC-1}

Immunohistochemical staining was performed manually, and each slide was carefully handled in strict accordance with the instructions. Anti-KK-LC-1 antibody (CL4762, Abcam, United Kingdom, $100 \mu \mathrm{L}$ ), produced in mice, was applied in the expression analysis. Immunohistochemical slide staining results were independently evaluated by two experienced pathologists. The $\mathrm{H}$-scoring system was used to evaluate KK-LC-1 staining results [26-29], and we estimated the $\mathrm{H}$-score by multiplying the total staining intensity of each section by the percentage of the number of positive cells. The staining intensity was divided into 4 levels varying from 0 to 3: 0 represents negative; 1 represents weak; 2 represents medium and 3 represents strong, and the percentage of positives was between 0 and 100. In general, the final $\mathrm{H}$-score obtained was between 0 and 300 . We stained KK-LC-1 in the cytoplasm and nucleus separately and obtained their respective values by scoring.

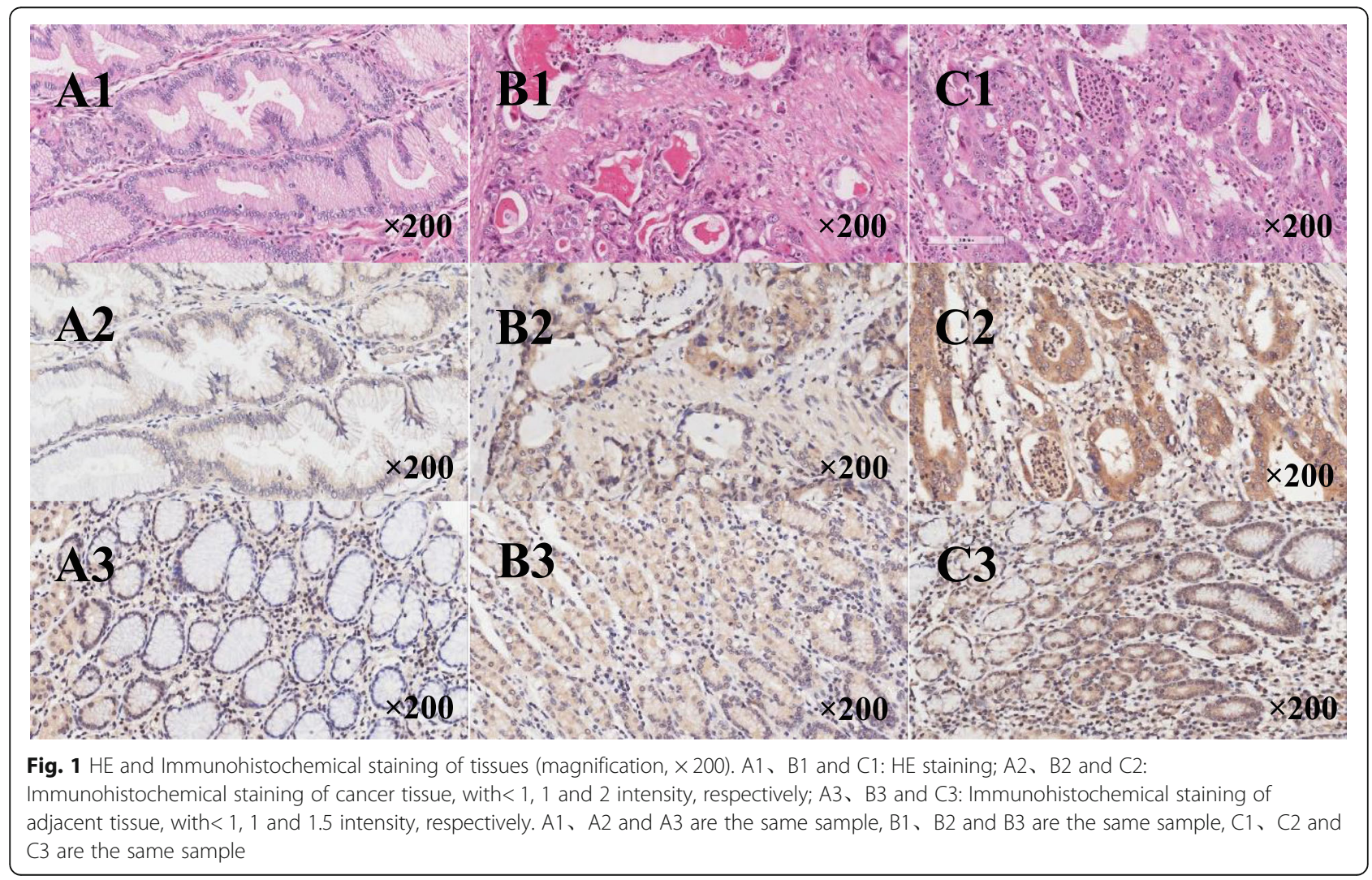


Table $3 \mathrm{H}$-score values in tumor and normal tissues

\begin{tabular}{llllll}
\hline Group & $\boldsymbol{n}$ & Localization & Minimum & Maximum & Median \\
\hline Tumor & 94 & Cytoplasm & 0 & 250 & 100 \\
Normal & 84 & Cytoplasm & 0 & 150 & 50 \\
\hline
\end{tabular}

\section{Statistical analysis}

This study used SPSS 17.0 software for statistical analysis. To evaluate sample distribution, the KolmogorovSmirnov nonparametric test was applied. The MannWhitney $U$ test was used to compare variables with abnormal distribution, and the chi-square test was used to compare qualitative variables. OS was compared with the Kaplan-Meier method and log rank test. All potential factors related to prognosis from univariate analysis were input into the Cox regression model. To identify independent prognostic factors, this paper applies multifactor Cox regression analysis. All $P$-values were bidirectional, and $P$-values that were less than 0.05 were considered to be statistically significant.

\section{Results}

\section{Clinicopathological characteristics and survival data}

The average and median ages of patients undergoing gastric cancer surgery were 65 and 66 (range 45-83 years old), respectively. Male patients comprised $75.5 \%$ of the study group, and the ratio of male to female patients was 3:1. Ninety-five percent of the patients underwent radical resection, of which moderately to highly differentiated adenocarcinoma was found in $24.4 \%$ of cases. Lymph node metastasis and distant metastasis was

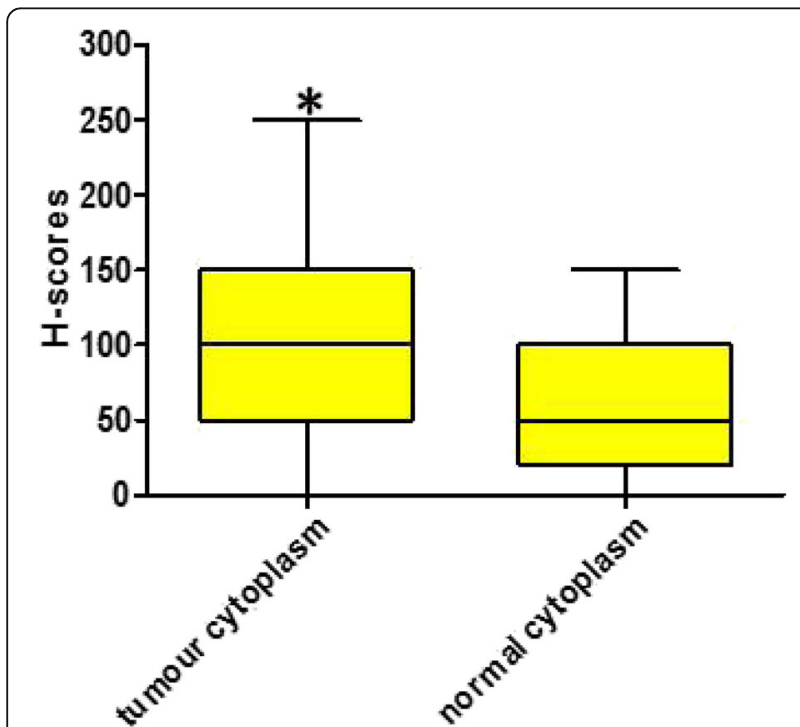

Fig. 2 Box plot of Kita-Kyushu lung cancer antigen-1 H scores in tumors and normal tissues. ${ }^{*}$ Indicates that there is a significant difference between the two groups, and the $P<0.001$
Table 4 Comparison in tumor and normal tissues for KitaKyushu lung cancer antigen-1 expression

\begin{tabular}{lllllll}
\hline Group & $\boldsymbol{n}$ & Minimum & Maximum & Median & Mean rank & $\boldsymbol{P}$ \\
\hline Tumor & 94 & 0 & 250 & 100 & 111.00 & $<0.001^{\mathrm{a}}$ \\
Normal & 84 & 0 & 150 & 50 & 65.44 & \\
\hline
\end{tabular}

aStatistically significant

found in 21.2 and $4 \%$ of patients, respectively. Table 1 lists more information about this result.

\section{Staining and H-scoring for KK-LC-1 expression}

KK-LC-1 staining was quantified and analysed (Table 2 and Fig. 1). In the tissue arrays, all stained specimens were located in the cytoplasm, and no strong positive $(3+)$ staining was found in the specimens. The H-scores of tumour tissue and normal tissue were calculated separately, and the empirical results are reported in Table 3 and Fig. 2. We found that the median H-score of KKLC-1 in the cytoplasm of tumour tissue was 100 (range $0-250)$. In normal tissues, we calculated that the median $\mathrm{H}$ score of KK-LC-1 was 50 (range 0-150).

\section{Comparisons and cut-off values of KK-LC-1 expression}

In both tumour and normal tissues, KK-LC-1 was found to be expressed only in the cytoplasm. As shown in the results of the Kolmogorov-Smirnov test, the $\mathrm{H}$ score values were abnormally distributed. Therefore, we chose the Mann-Whitney U test to analyse the data (Table 4). In normal tissues and tumour tissues, KK-LC-1 is expressed only in the cytoplasm. At the same time, we observed that KK-LC-1 expression was higher in tumour tissues than in normal tissues $(P<0.001)$.

Due to the difference in the median $\mathrm{H}$ score of tissue staining, all GC patients were divided into two subsamples. Univariate and multivariate analysis results indicated that favourable OS (as displayed in Fig. 3a) was generally associated with high $\mathrm{H}$-scores in the cytoplasm. Univariate survival analysis (Table 5) showed that KK-LC-1 expression $(P=0.016)$, T stage $(P=0.002), \mathrm{N}$ stage $(P=0.001)$ and clinical stage $(P<0.001)$ were associated with $O S$ in GC. In our study, age, sex, tumour size, $M$ stage and pathological grade had no significant effect. The empirical results of $\mathrm{CoS}$ regression analysis showed that $\mathrm{T}$ stage, $\mathrm{N}$ stage and higher expression of KK-LC-1 protein were independent prognostic factors of OS (Table 5).

\section{Correlations between KK-LC-1 expression and clinicopathological parameters}

In Table 6, we marked the association between KK-LC-1 expression and the clinicopathological data in detail. KKLC-1 expression was not significantly associated with age, sex, tumour size, TNM stage or clinical stage. However, patients with a low pathological grade and those with intestinal-type GC exhibited relatively high expression of 
A

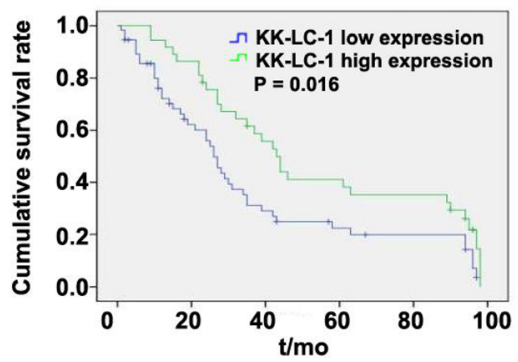

C

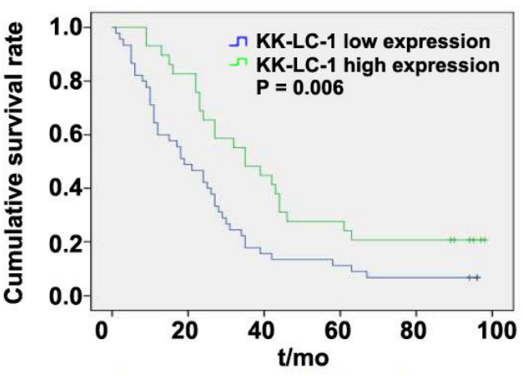

$\mathbf{E}$

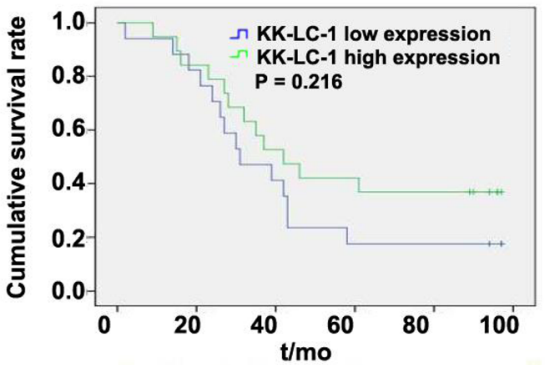

G

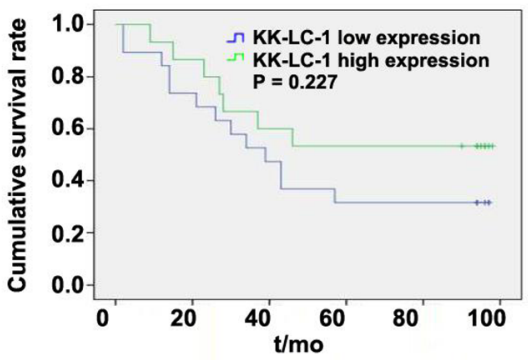

B

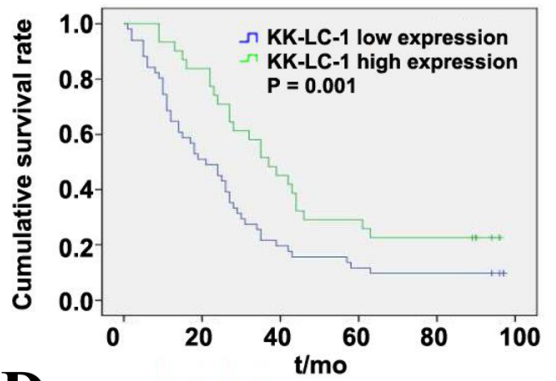

D

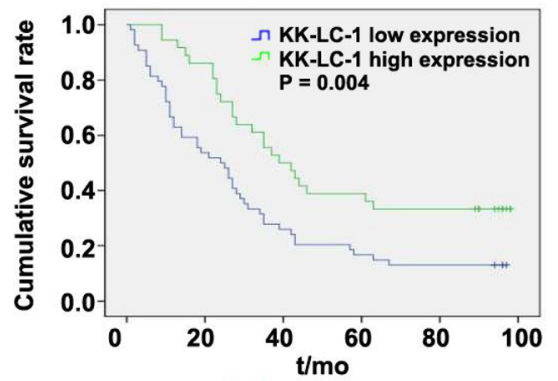

$\mathbf{F}$

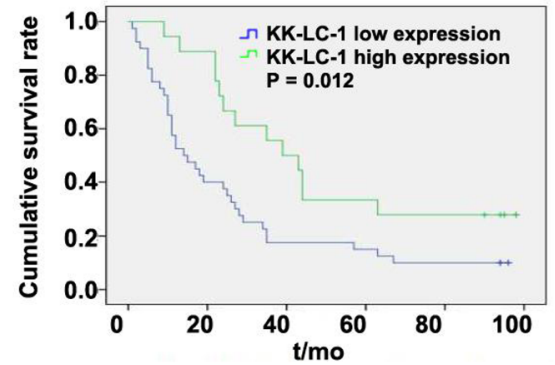

$\mathbf{H}$

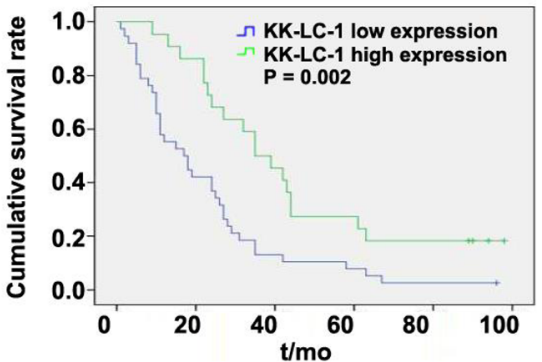

Fig. 3 Kaplan-Meier survival analyses in different subgroups, according to Kita-Kyushu lung cancer antigen-1 expression. a: The whole cohort; b: T3 + 4 group; c: Positive Nodal involvement group; d: M0 group; e: Pathological grades <Ill group; f: Pathological grades $\geq$ Ill; $\mathbf{g}$ : Pathological Stage I + II group; h: Pathological Stage III + IV group. KK-LC-1: Kita-Kyushu lung cancer antigen-1

the KK-LC-1 protein, and the $P$ value was statistically significant.

\section{Discussion}

In this study, GC patients with higher levels of KK-LC-1 expression were found to have a better prognosis, and the overall expression of KK-LC-1 protein in gastric cancer tissue was higher than that in normal tissues. Fukuyama et al. [30] found similar results: KK-LC-1 gene expression was found to be higher in tumour regions than in non-tumour regions, and KK-LC-1 was found to be expressed in non-tumour sites carrying stomach 
Table 5 Univariate and multivariate analyses for Gastric cancer

\begin{tabular}{llll}
\hline Univariate & $\mathbf{X}^{\mathbf{2}}$ & $\boldsymbol{P}$ value & OR $(\mathbf{9 5} \% \mathbf{C l})$ \\
\hline Age & 0.577 & 0.565 & \\
Sex & 0.871 & 0.351 & \\
Tumor Size & 2.632 & 0.105 & \\
T Stage & 9.868 & $0.002^{\mathrm{a}}$ & \\
N Stage & 11.973 & $0.001^{\mathrm{a}}$ & \\
M Stage & 1.873 & 0.053 & \\
Pathological grades & 3.753 & 0.171 & \\
Pathological Stage & 10.464 & $0.001^{\mathrm{a}}$ & \\
Protein Expression & 5.848 & $0.016^{\mathrm{a}}$ & \\
Multivariate & & & \\
\multicolumn{1}{l}{ T Stage } & & $0.007^{\mathrm{a}}$ & $3.466(1.394-8.622)$ \\
$\quad$ N Stage & & $0.009^{\mathrm{a}}$ & $2.986(1.308-6.814)$ \\
$\quad$ Protein Expression & & $0.034^{\mathrm{a}}$ & $0.591(0.364-0.961)$ \\
\hline a Statistically significant & & &
\end{tabular}

tumour tissue. In our experimental findings, the KK-LC1 protein expression rate in tumour tissues was $95.7 \%$. In contrast, Akiko et al. found that the gene expression rate of $\mathrm{KK}-\mathrm{LC}-1$ reached $81.6 \%$, which was significantly higher than that found in other studies [23]. One study found that the KK-LC-1 expression rate in triplenegative breast cancer was $75 \%$ [31].. These findings are similar to ours, which suggests that KK-LC-1 is likely to be highly expressed in tumours. However, no existing studies have focused on the expression of tumourassociated antigens in gastric cancer as highly expressed as KK-LC-1, suggesting that KK-LC-1 could be an ideal therapeutic target. For clinical diagnostic applications, high expression of tumour-associated antigens in the early stages of cancer is often considered a useful target. At present, there are few reports on KK-LC-1 gene and protein expression and tumour prognosis. Thus, more research is needed for verification.

Generally, this study's findings suggest that there is a significant negative correlation between KK-LC-1 protein expression and pathological grade. The higher the pathological grade is, the lower the KK-LC-1 protein expression in the tissue and the poorer the prognosis. In contrast, the lower the pathological grade is, the higher the KK-LC-1 protein expression in the tissue and the better the prognosis of the patient. This result also indirectly shows the reliability of our experimental data. We hypothesized that the KK-LC-1 protein is associated with the early stage of the tumour and thus related to a good prognosis. Therefore, KK-LC-1 can be used as a positive biomarker directly related to prognosis and provides clinicians with more choices. For example, patients with higher KK-LC-1 protein expression levels may achieve better results from adjuvant chemotherapy or radiotherapy than patients with lower expression levels.
Table 6 Correlation between KK-LC-1 expression and clinicopathological parameters in tumor

\begin{tabular}{|c|c|c|c|c|}
\hline Parameter & Low expression & High expression & $x^{2}$ & $P$ value \\
\hline \multicolumn{5}{|l|}{ Age } \\
\hline$\leq 65$ & 29 & 15 & 0.963 & 0.326 \\
\hline$>65$ & 28 & 22 & & \\
\hline \multicolumn{5}{|l|}{ Sex } \\
\hline Female & 15 & 8 & 0.268 & 0.605 \\
\hline Male & 42 & 29 & & \\
\hline \multicolumn{5}{|c|}{ Tumor Size (cm) } \\
\hline$\leq 5$ & 21 & 17 & 0.772 & 0.380 \\
\hline$>5$ & 36 & 20 & & \\
\hline \multicolumn{5}{|l|}{ T Stage } \\
\hline $\mathrm{T} 1+2$ & 6 & 6 & 0.652 & 0.419 \\
\hline $\mathrm{T} 3+4$ & 51 & 31 & & \\
\hline \multicolumn{5}{|l|}{ M Stage } \\
\hline MO & 54 & 36 & 0.361 & 0.548 \\
\hline M1 & 3 & 1 & & \\
\hline \multicolumn{5}{|l|}{ N Stage } \\
\hline Negative & 12 & 8 & 0.004 & 0.947 \\
\hline Positive & 45 & 29 & & \\
\hline \multicolumn{5}{|c|}{ Pathological grades } \\
\hline$<111$ & 17 & 19 & 4.400 & $0.036^{\mathrm{a}}$ \\
\hline$\geq I I I$ & 40 & 18 & & \\
\hline \multicolumn{5}{|l|}{ Clinical Stage } \\
\hline $\mid+\|$ & 19 & 15 & 0.505 & 0.477 \\
\hline$I I I+I V$ & 38 & 22 & & \\
\hline \multicolumn{5}{|l|}{ Histological } \\
\hline Intestinal type & 17 & 22 & 7.072 & $0.008^{\mathrm{a}}$ \\
\hline Diffuse type & 39 & 16 & & \\
\hline
\end{tabular}

${ }^{\text {a }}$ tatistically significant

However, studies have also shown that the expression level of KK-LC-1 in hepatocellular carcinoma (HCC) is increased. High KK-LC-1 expression levels are associated with poor survival outcomes in HCC. This study also found that KK-LC-1 promotes cell growth, invasion, migration and epithelial-mesenchymal transition in vivo and in vitro [30]. In summary, abnormal KK-LC-1 protein expression is clearly related to the occurrence and development of tumours. Therefore, KK-LC-1 may play different roles in different malignant tumours, and more in-depth research is required to verify the true relationship between KK-LC-1 and cancer and the specific mechanisms of involvement.

According to the classification proposed by Lauren, GC can be divided into 2 histological types under microscopic examination, namely, the intestinal type and the diffuse type. Intestinal GCs originate from premalignant 
lesions, initially chronic gastritis caused by Helicobacter pylori, followed by atrophic and metaplastic gastritis. However, diffuse GC is directly induced by active inflammation of the gastric mucosa [32, 33]. Generally, the diffuse type has a poor prognosis and a higher risk of lymph node metastasis (LNM), while the intestinal type has a better prognosis [34].. Our experimental results are consistent with this conclusion. KK-LC-1 is highly expressed in the intestinal type, and the prognosis is good.

To date, some mechanisms linking KK-LC-1 and neoplasia have been revealed in several tumours. According to reports, the activation of CT genes in some types of cancer is related to hypomethylation of CpG islands. CT45 is one of the 6 member families of the X-linked CT gene, and the expression of CT45 associated with hypomethylation of promoter DNA is increased in epithelial ovarian cancer. Researchers believe that CT45 expression may be a prognostic biomarker [35].. In lung adenocarcinoma, PIWIL1 is considered to be a highly expressed CT gene. Hypomethylation of the promoter DNA of PIWIL1 can cause overexpression of CT genes [36]. However, to date, there are few reports on the function and mechanism of KK-LC-1 in human malignant tumours.

It is worth noting that our research findings can be regarded as a theoretical basis for immunotherapy and targeted therapy of different tumours involving KK-LC1. Based on the Human Protein Atlas database (http:// www.proteinatlas.org), CT83 transcripts are expressed in various tumour cell lines, including gastric cancer, colorectal cancer, breast cancer, urothelial cancer, lung cancer, and cervical cancer. We speculate that CT83 may be related to the body's antitumour response. In normal tissues, the expression level of CT83 is very low. However, when a tumour develops, the CT83 expression level may increase as part of the immune response to the tumour. A higher CT83 expression level indicates a stronger ability of the body to resist tumours and therefore a better prognosis. In studies of the early diagnosis of GC, researchers such as Futawatari found that a higher CT83 expression rate can often be detected early [24]. Therefore, CT83 can be used as a potential marker for the early diagnosis and treatment of GC.

Our study has some potential limitations. This is a single study with relatively few sample cases and few statistical analysis tools. Finally, some patients received postoperative chemotherapy or radiotherapy. Although the survival period was limited, the results did not consider the impact of these adjuvant therapies on prognosis. Therefore, further research and multi-angle studies are needed to explore KK-LC-1 expression in GC, and the clinical efficiency of KK-LC-1 needs to be evaluated in a wider range of patients. In summary, our project indicates that $\mathrm{KK}-\mathrm{LC}-1$ protein expression in $\mathrm{GC}$ is higher than that in neighbouring tissues. High levels of KK-LC-1 protein expression are associated with longer overall survival in GC. KK-LC-1 is a good biomarker for patients with GC.

\section{Conclusions}

In summary, our project indicates that KK-LC-1's protein expression in $\mathrm{GC}$ is higher than that in neighboring tissues. High levels of $\mathrm{KK}-\mathrm{LC}-1$ protein expression are associated with longer overall survival in GC. KK-LC-1 is a good biomarker for patients with GC.

\section{Acknowledgments}

Thanks to the staff of Department of Gastrointestinal Surgery, Key Laboratory of Carcinogenesis and Translational Research (Ministry of Education), Peking University Cancer Hospital \& Institute for their support in the experiment.

\section{Authors' contributions}

$\mathrm{JJ}$ and $\mathrm{YL}$ designed the study and wrote the manuscript. AQ W and JH C helped with data management and carried out statistical analysis. Teachers WZ and JH G classify the tissues after immunohistochemical staining. LP L and $\mathrm{YL}$ performed project administration. All authors have read and approved the manuscript.

\section{Funding}

This study was funded by Research Program of science and technology at Universities of Inner Mongolia Autonomous Region (NJZZ18184). This funding provided partial financial support for this experiment.

\section{Availability of data and materials}

The datasets used and/or analysed during the current study are available from the corresponding author on reasonable request.

\section{Declarations}

Ethics approval and consent to participate

This study was approved by the Ethics Committee of Shanghai Outdo Biotech Company. The patients enrolled all presented written informed consent.

Consent for publication

Not applicable.

\section{Competing interests}

No conflicts of interest declared.

\section{Author details}

'Department of Gastrointestinal Surgery, Shandong Provincial Hospital, Cheeloo College of Medicine, Shandong University, Jinan 250021, Shandong, China. ${ }^{2}$ First Affiliated Hospital of Baotou Medical College, General Surgery, Baotou 014010, Inner Mongolia, China. ${ }^{3}$ Department of Gastrointestinal Surgery, Key Laboratory of Carcinogenesis and Translational Research (Ministry of Education), Peking University Cancer Hospital \& Institute, Beijing 100142, China. ${ }^{4}$ Baotou Medical College, Inner Mongolia University of Science \& Technology, Baotou 014060, Inner Mongolia, China. ${ }^{5}$ Department of Gastrointestinal Surgery, Shandong Provincial Hospital Affiliated to Shandong First Medical University, Jinan 250021, Shandong, China.

Received: 31 July 2020 Accepted: 25 February 2021

Published online: 12 March 2021

\section{References}

1. Katai H, Ishikawa T, Akazawa K, Isobe Y, Miyashiro I, Oda I, Tsujitani S, Ono H, Tanabe S, Fukagawa T, Nunobe S, Kakeji Y, Nashimoto A. Five-year survival analysis of surgically resected gastric cancer cases in Japan: a retrospective analysis of more than 100,000 patients from the nationwide registry of the 
Japanese gastric Cancer association (2001-2007). Gastric Cancer. 2018;21(1): 144-54.

2. Shi C, Liu B, Yan J, Liu H, Pan Z, Yao W, Yan F, Zhang H. Gastric Cancer: preoperative TNM staging with individually adjusted computed tomography scanning phase. J Comput Assist Tomogr. 2016;40(1):160-6

3. Aoyagi K, Kouhuji K, Kizaki J, Isobe T, Hashimoto K, Shirouzu K. Molecular targeting to treat gastric cancer. World J Gastroenterol. 2014;20(38):13741-55.

4. Pectasides D, Mylonakis A, Kostopoulou M, Papadopoulou M, Triantafillis D, Varthalitis J, Dimitriades M, Athanassiou A. CEA, CA 19-9, and CA-50 in monitoring gastric carcinoma. Am J Clin Oncol. 1997;20(4):348-53.

5. Aloe S, D'Alessandro R, Spila A, Ferroni P, Basili S, Palmirotta R, Carlini M, Graziano F, Mancini R, Mariotti S, Cosimelli M, Roselli M, Guadagni F. Prognostic value of serum and tumor tissue CA 72-4 content in gastric cancer. Int J Biol Markers. 2003;18(1):21-7.

6. Genc CG, Falconi M, Partelli S, Muffatti F, van Eeden S, Doglioni C, Klumpen $\mathrm{HJ}$, van Eijck C, Nieveen VDE. Recurrence of pancreatic neuroendocrine tumors and survival predicted by Ki67. Ann Surg Oncol. 2018;25(8):2467-74.

7. Sohn BH, Hwang JE, Jang HJ, Lee HS, Oh SC, Shim JJ, Lee KW, Kim EH, Yim SY, Lee SH, Cheong JH, Jeong W, Cho JY, Kim J, Chae J, Lee J, Kang WK, Kim S, Noh SH, Ajani JA, Lee JS. Clinical Significance of Four Molecular Subtypes of Gastric Cancer Identified by The Cancer Genome Atlas Project. Clin Cancer Res. 2017.

8. Yang TS, Yang XH, Wang XD, Wang YL, Zhou B, Song ZS. MiR-214 regulate gastric cancer cell proliferation, migration and invasion by targeting PTEN. Cancer Cell Int. 2013;13(1):68

9. Ha SY, Lee J, Kang SY, Do IG, Ahn S, Park JO, Kang WK, Choi MG, Sohn TS, Bae JM, Kim S, Kim M, Kim S, Park CK, Ignatius OS, Kim KM. MET overexpression assessed by new interpretation method predicts gene amplification and poor survival in advanced gastric carcinomas. Mod Pathol. 2013;26(12):1632-41.

10. Lee SJ, Lee J, Park SH, Park JO, Lim HY, Kang WK, Park YS, Kim ST. C-MET overexpression in colorectal Cancer: a poor prognostic factor for survival. Clin Colorectal Cancer. 2018;17(3):165-9.

11. Pasquini G, Giaccone G. C-MET inhibitors for advanced non-small cell lung cancer. Expert Opin Investig Drugs. 2018;27(4):363-75.

12. Scanlan MJ, Gure AO, Jungbluth AA, Old LJ, Chen YT. Cancer/testis antigens: an expanding family of targets for cancer immunotherapy. Immunol Rev. 2002;188:22-32

13. Simpson AJ, Caballero OL, Jungbluth A, Chen YT, Old L. Cancer/testis antigens, gametogenesis and cancer. Nat Rev Cancer. 2005;5(8):615-25.

14. Jager $D$, Jager $E$, Knuth $A$. Immune responses to tumour antigens: implications for antigen specific immunotherapy of cancer. J Clin Pathol. 2001;54(9):669-74.

15. Li G, Miles A, Line A, Rees RC. Identification of tumour antigens by serological analysis of cDNA expression cloning. Cancer Immunol Immunother. 2004;53(3):139-43.

16. Mischo A, Kubuschok B, Ertan K, Preuss KD, Romeike B, Regitz E, Schormann C, de Bruijn D, Wadle A, Neumann F, Schmidt W, Renner C, Pfreundschuh M. Prospective study on the expression of cancer testis genes and antibody responses in 100 consecutive patients with primary breast cancer. Int J Cancer. 2006;118(3):696-703.

17. Bricard G, Bouzourene H, Martinet O, Rimoldi D, Halkic N, Gillet M, Chaubert P, Macdonald HR, Romero P, Cerottini JC, Speiser DE. Naturally acquired MAGE-A10- and SSX-2-specific CD8+ T cell responses in patients with hepatocellular carcinoma. J Immunol. 2005:174(3):1709-16.

18. Groeper C, Gambazzi F, Zajac P, Bubendorf L, Adamina M, Rosenthal R, Zerkowski HR, Heberer M, Spagnoli GC. Cancer/testis antigen expression and specific cytotoxic T lymphocyte responses in non small cell lung cancer. Int J Cancer. 2007;120(2):337-43.

19. Ghafouri-Fard S, Modarressi MH. Cancer-testis antigens: potential targets for cancer immunotherapy. Arch Iran Med. 2009;12(4):395-404.

20. Gjerstorff MF, Andersen MH, Ditzel HJ. Oncogenic cancer/testis antigens: prime candidates for immunotherapy. Oncotarget. 2015;6(18):15772-87.

21. Ogata K, Aihara R, Mochiki E, Ogawa A, Yanai M, Toyomasu Y, Ando H, Ohno T, Asao T, Kuwano H. Clinical significance of melanoma antigenencoding gene-1 (MAGE-1) expression and its correlation with poor prognosis in differentiated advanced gastric cancer. Ann Surg Oncol. 2011: 18(4):1195-203.

22. Honda T, Tamura G, Waki T, Kawata S, Terashima M, Nishizuka S, Motoyama T. Demethylation of MAGE promoters during gastric cancer progression. $\mathrm{Br}$ J Cancer. 2004;90(4):838-43.
23. Shida A, Futawatari N, Fukuyama T, Ichiki Y, Takahashi Y, Nishi Y, Kobayashi $\mathrm{N}$, Yamazaki H, Watanabe M. Frequent high expression of Kita-Kyushu lung Cancer Antigen-1 (KK-LC-1) in gastric Cancer. Anticancer Res. 2015;35(6): 3575-9.

24. Futawatari N, Fukuyama T, Yamamura R, Shida A, Takahashi Y, Nishi Y, Ichiki Y, Kobayashi N, Yamazaki H, Watanabe M. Early gastric cancer frequently has high expression of KK-LC-1, a cancer-testis antigen. World J Gastroenterol. 2017;23(46):8200-6.

25. Chen J, Wang A, Ji J, Zhou K, Bu Z, Lyu G, Ji J. An innovative prognostic model based on four genes in Asian patient with gastric Cancer. Cancer Res Treat. 2021:53(1):148-61.

26. Yeo W, Chan SL, Mo FK, Chu CM, Hui JW, Tong JH, Chan AW, Koh J, Hui EP, Loong H, Lee K, Li L, Ma B, To KF, Yu SC. Phase I/II study of temsirolimus for patients with unresectable hepatocellular carcinoma (HCC)- a correlative study to explore potential biomarkers for response. BMC Cancer. 2015;15:395.

27. Specht E, Kaemmerer D, Sanger J, Wirtz RM, Schulz S, Lupp A. Comparison of immunoreactive score, HER2/neu score and $\mathrm{H}$ score for the immunohistochemical evaluation of somatostatin receptors in bronchopulmonary neuroendocrine neoplasms. Histopathology. 2015;67(3):368-77.

28. Liang PI, Li CF, Chen LT, Sun DP, Chen TJ, Hsing CH, Hsu HP, Lin CY. BCL6 overexpression is associated with decreased p19 ARF expression and confers an independent prognosticator in gallbladder carcinoma. Tumour Biol. 2014;35(2):1417-26.

29. Budwit-Novotny DA, McCarty KS, Cox EB, Soper JT, Mutch DG, Creasman WT, Flowers JL, McCarty KJ. Immunohistochemical analyses of estrogen receptor in endometrial adenocarcinoma using a monoclonal antibody. Cancer Res. 1986;46(10):5419-25.

30. Fukuyama T, Futawatari N, Yamamura R, Yamazaki T, Ichiki Y, Ema A, Ushiku H, Nishi Y, Takahashi Y, Otsuka T, Yamazaki H, Koizumi W, Yasumoto K, Kobayashi N. Expression of KK-LC-1, a cancer/testis antigen, at non-tumour sites of the stomach carrying a tumour. Sci Rep. 2018;8(1):6131.

31. Paret C, Simon P, Vormbrock K, Bender C, Kolsch A, Breitkreuz A, Yildiz O, Omokoko T, Hubich-Rau S, Hartmann C, Hacker S, Wagner M, Roldan DB, Selmi A, Tureci O, Sahin U. CXorf61 is a target for T cell based immunotherapy of triple-negative breast cancer. Oncotarget. 2015;6(28): 25356-67.

32. Watanabe M, Kato J, Inoue I, Yoshimura N, Yoshida T, Mukoubayashi C, Deguchi H, Enomoto S, Ueda K, Maekita T, Iguchi M, Tamai H, Utsunomiya H, Yamamichi N, Fujishiro M, Iwane M, Tekeshita T, Mohara O, Ushijima T, Ichinose M. Development of gastric cancer in nonatrophic stomach with highly active inflammation identified by serum levels of pepsinogen and helicobacter pylori antibody together with endoscopic rugal hyperplastic gastritis. Int J Cancer. 2012;131(11):2632-42.

33. Nardone G, Rocco A, Malfertheiner P. Helicobacter pylori and molecular events in precancerous gastric lesions. Aliment Pharm Ther. 2004;20(3):261-70.

34. Lee T, Tanaka H, Ohira M, Okita Y, Yoshii M, Sakurai K, Toyokawa T, Kubo N, Muguruma K, Tanaka S, Ohsawa M, Hirakawa K. Clinical impact of the extent of lymph node micrometastasis in undifferentiated-type early gastric Cancer. Oncology. 2014;86(4):244-52.

35. Zhang W, Barger CJ, Link PA, Mhawech-Fauceglia P, Miller A, Akers SN, Odunsi K, Karpf AR. DNA hypomethylation-mediated activation of Cancer/testis antigen 45 (CT45) genes is associated with disease progression and reduced survival in epithelial ovarian cancer. Epigenetics-US. 2015;10(8):736-48.

36. Xie K, Zhang K, Kong J, Wang C, Gu Y, Liang C, Jiang T, Qin N, Liu J, Guo X, Huo R, Liu M, Ma H, Dai J, Hu Z. Cancer-testis gene PIWIL1 promotes cell proliferation, migration, and invasion in lung adenocarcinoma. Cancer Med. 2018;7(1):157-66.

\section{Publisher's Note}

Springer Nature remains neutral with regard to jurisdictional claims in published maps and institutional affiliations. 